\title{
Huge Juvenile Polyps of the Stomach: A Case Report
}

\author{
Tsutomu Nishida $^{1 *}$, Hirotsugu Saiki ${ }^{1,2}$, Masashi Yamamoto ${ }^{1}$, Shiro Hayashi ${ }^{1}$, Tokuhiro Matsubara ${ }^{1}$, Sachiko \\ Nakajima $^{1}$, Masashi Hirota ${ }^{3}$, Hiroshi Imamura ${ }^{3}$, Ryoji Kushima ${ }^{4}$, Shiro Adachi ${ }^{5}$ and Masami Inada $^{1}$ \\ ${ }^{1}$ Department of Gastroenterology, Toyonaka Municipal Hospital, Japan
}

${ }^{2}$ Department of Gastroenterology, Japan Community Health Care Organization Osaka Hospital, Japan

${ }^{3}$ Department of Surgery, Toyonaka Municipal Hospital, Japan

${ }^{4}$ Department of Clinical Laboratory Medicine, Shiga University of Medical Science, Japan

${ }^{5}$ Department of Pathology, Toyonaka Municipal Hospital, Japan

Submission: July 10, 2017; Published: July 18, 2017

"Corresponding author: Tsutomu Nishida, Department of Gastroenterology, Toyonaka municipal Hospital, 4-14-1 Shibahara, Toyonaka, Osaka 5608565, Japan, Tel: +81668430101; Fax: +81668583531; Email: tnishida.gastro@gmail.com

\begin{abstract}
A 46-year-old man with no familial history of polyposis presented with diarrhea for 2 months. Laboratory data showed anemia, and mild hypoproteinemia. Computed tomography shows two huge tumors in the stomach. Esophagogastroduodenoscopy showed two huge polyps and giant folds covering nodular mucosa in the stomach. Chromoendoscopy with indigo carmine showed that polyps with finger-like villous mucosa were partially reddish and had much mucin. All biopsy specimens from the polyps and randomly collected gastric mucosa indicated hyperplastic changes. Colonoscopy showed several sporadic adenomatous polyps. We diagnosed the patient with huge gastric hyperplastic polys causing protein losing and anemia and sporadic colonic adenomatous polyps. We performed gastrectomy. Immediately after surgery, he stopped diarrhea and recovered hemoglobin and serum protein levels. Histological examinations revealed that hyperplastic glands with cystically dilated glands were separated by abundant connective tissue. Focal dysplastic change in the foveolar epithelium was found. Finally, we diagnosed juvenile polyps with focal dysplasia limited to the stomach.
\end{abstract}

Keywords: Gastric juvenile polyp; Gastric polyp; Protein losing gastroenteropathy

\section{Introduction}

Juvenile polyposis is a syndrome presented with multiple hamartomatous polyps and generally defined as the occurrence of dozens or hundreds of juvenile polyps of the gastrointestinal tract. Juvenile polyps may develop sporadically or may be associated with the familial juvenile polyposis syndrome (JPS). Patients with JPS are at increased for colorectal and gastric cancer [1].

Juvenile polyposis are divided into three categories;

i. Juvenile polyposis of infancy

ii. Juvenile polyposis coli, and

iii. Generalized juvenile polyposis [2].

Watanabe et al. [3] first reported a case of juvenile polyposis of the stomach in 1979. Since after, it was proposed as the fourth category of juvenile polyposis [4]. Juvenile polyposis of the stomach is, however, difficult to diagnose because of rare phenotype and difficulty of differential diagnosis between juvenile polyp and foveolar hyperplastic polyp histologically by biopsy specimens. We herein report a case of juvenile polyposis of the stomach.

\section{Case Report}

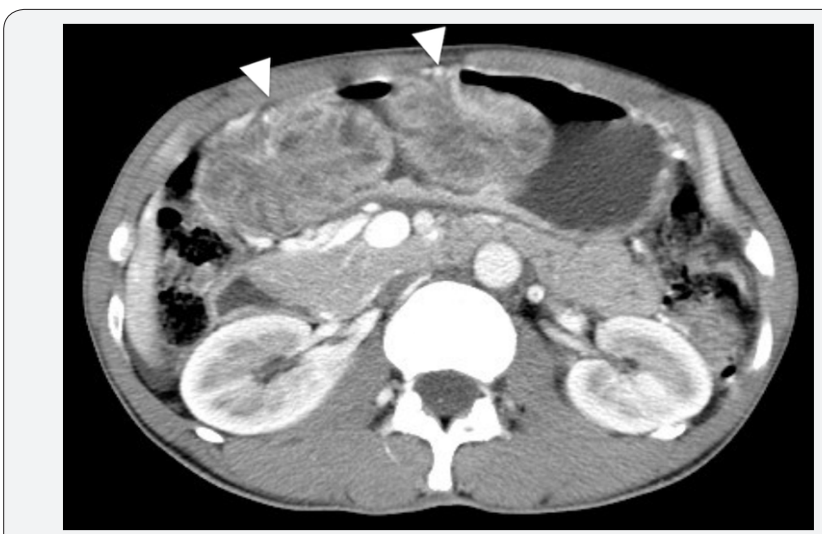

Figure 1: Computed tomography showed two huge tumors in the stomach (Arrows). 


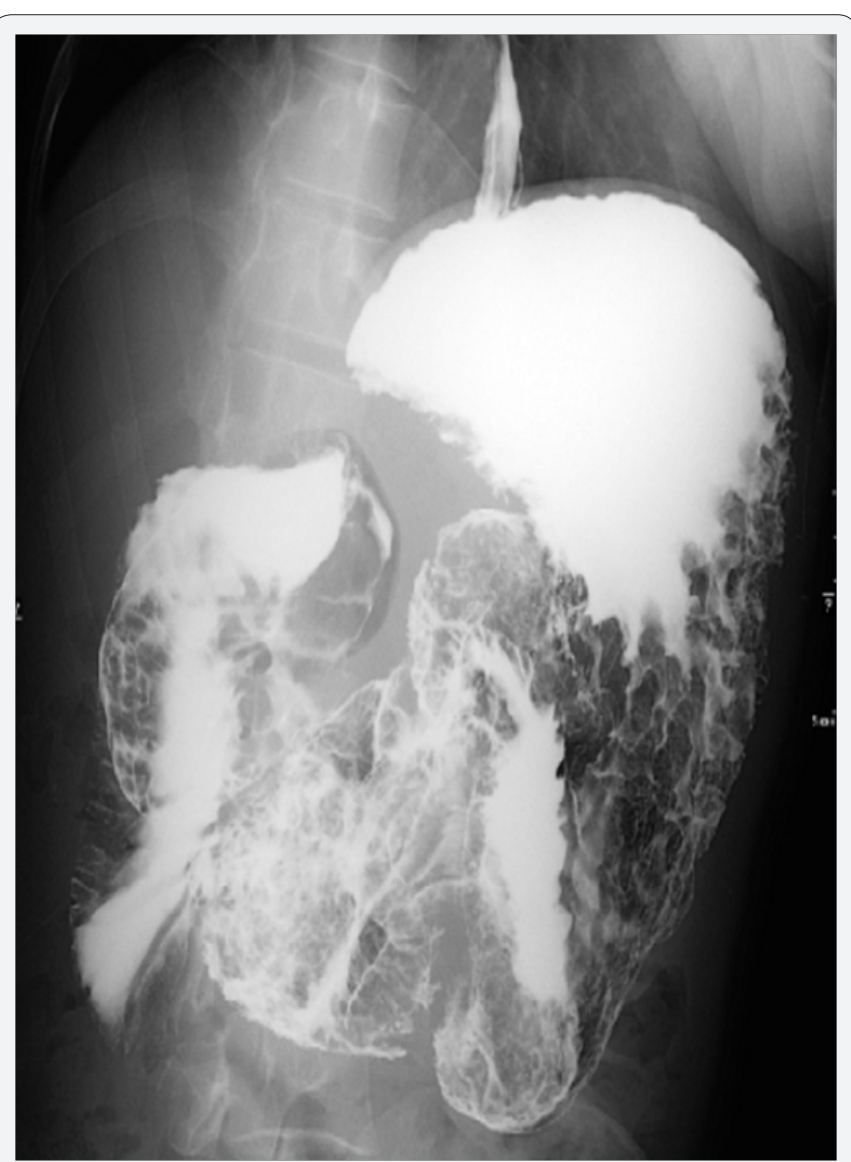

Figure 2: Double-contrast barium study showed numerous gastric polyps so called soap-bubble sign predominantly in the anturum.

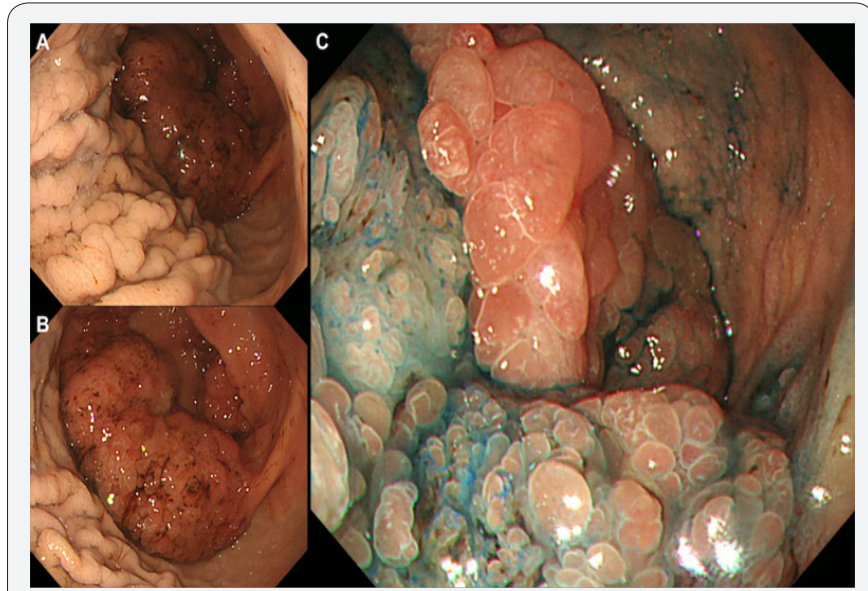

Figure 3: Esophagogastroduodenoscopy showed the mucosa in the corpus (A) and fornix was nodular which formed giant folds and there were two huge polyps in the greater curvature of the body (B) and the antrum. Chromoendoscopy with indigo carmine showed that polyps with finger-like villous mucosa were partially reddish and had much mucin $(C)$.

A 46-year-old man with no familial history of polyposis presented with diarrhea for 2 months. Laboratory data showed anemia (hemoglobin $7.1 \mathrm{~g} / \mathrm{dL}$ ), mild hypoproteinemia (total protein $5.4 \mathrm{~g} / \mathrm{dL}$, albumin $3.0 \mathrm{~g} / \mathrm{dL}$ ) and negative for anti-H. pylori anti-body. He presented with no abnormality of the ectodermalderived tissues, including skin or nail. Computed tomography showed two huge tumors in the stomach (Figure 1). Doublecontrast barium study showed numerous gastric polyps (Figure 2). Esophagogastroduodenoscopy showed edematous giant folds covering nodular mucosa in the gastric body (Figure 3A) and two huge polyps in the greater curvature of the body (Figure 3B) and the antrum. Chromoendoscopy with indigo carmine showed that edematous polyps with of finger-like, different sized, villous appearances were partially reddish and had much mucin (Figure 3C). All biopsy specimens from the polyps and randomly collected gastric mucosa indicated hyperplastic changes and no evidence of dysplasia or carcinoma was present. Colonoscopy showed several sporadic adenomatous polyps. We diagnosed him with huge gastric hyperplastic polys causing protein losing and anemia and sporadic colonic adenomatous polyps. We performed distal gastrectomy and colon polypectomy. Resected specimens showed that nearly the entire stomach was covered with numerous villous mucosa and there were two large pedunculated polyps in the greater curvature of the body and the antrum (Figure 4). Histological examinations revealed that hyperplastic glands with cystically dilated glands were separated by abundant connective tissue. Focal dysplastic change in the foveolar epithelium was found (Figure 5A \& 5B). Histology of colon polyps were adenomaouts polyps including mucosal adenocarcinoma. Immediately after surgery in a month, he stopped diarrhea and recovered anemia and serum protein levels. After that, we examined the small intestine by barium studies but no polypoid lessons were detected. Finally, we diagnosed juvenile polyposis of the stomach with focal dysplasia.

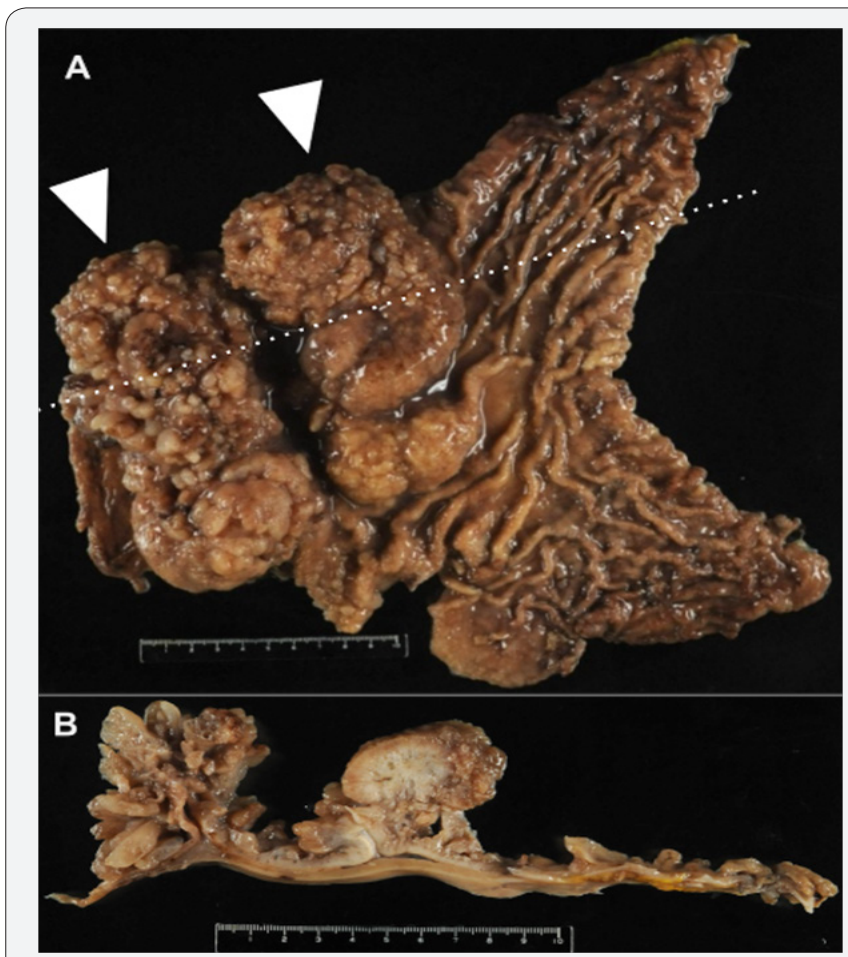

Figure 4: Macroscopic view of the surgical specimen (A) and the divided view (B). Nearly the entire stomach was covered with numerous villous mucosa. Arrows showed the large pedunculated polyp in the greater curvature of the body $(12 \times 6 \mathrm{~cm})$ and the antrum $(15 \times 7 \mathrm{~cm})$. 


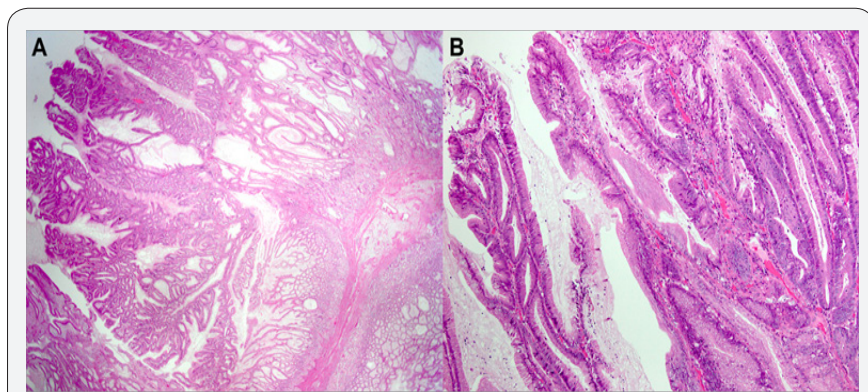

Figure 5: Histologic examination revealed that hyperplastic glands were separated by abundant connective tissue, closely resembling hyperplastic polyp except for the absence of active inflammatory changes. Cystically dilated glands were also observed in the hyperplastic lesion (A). Focal dysplastic change in the foveolar epithelium was found although most of the epithelial component did not show significant atypia (B).

Nine months later, surveillance EGD showed nodular mucosa grew into polypoid lesions with remarkable reddens in the remnant stomach. We could not deny those polypoid lesions had dysplasia or neoplasms and then we performed total gastrectomy of the remnant stomach. There was no neoplastic lesion in the remnant stomach. After 2 years after second surgery, no juvenile polyposis developed in the small intestine and the colon by surveillance colonoscopy and barium study.

\section{Discussion}

Juvenile polyps may develop sporadically or may be associated with the familial JPS that are generally defined as the occurrence of dozens or hundreds of hamartomatous polyps in the gastrointestinal tract, specifically in the stomach, small intestine, colon, and rectum.

The diagnosis of JPS can be clinically made if any following conditions are present;

i. More than five colorectal juvenile polyps,

ii. Multiple juvenile polyps throughout the gastrointestinal tract, or

iii. One or more juvenile polyps with a family history of juvenile polyps.

Juvenile polyps develop from infancy within the first few years of life through adulthood and are accompanied by hypoproteinemia, protein-losing enteropathy, diarrhea, anemia, and edema. JPS is an autosomal dominant condition reported to be associated with germline mutation in the SMAD4 or bone morphogenetic protein receptor type-1A (BMPR1A) genes [5,6], which are related to the transforming growth factor-beta (TGFbeta) signaling pathway [7]. When BMPR1A is activated through phosphorylation, it phosphorylates SMAD family proteins [5]. Mutation of those genes are observed in about $60 \%$ of patients with JPS. About $25 \%$ of patients have de novo mutations.

Sporadic juvenile polyps of the colon are considered benign and occur in up to $2 \%$ of children under the age of 10 years [8].
Most of them are solitary and do not require further follow-up [9]. In contrast, patients with JPS who range from $9 \%$ to $50 \%$ can develop malignant transformation $[1,7,10]$. In the present case, it was difficult to diagnose this case as JPS prior to the surgery because all biopsy specimens indicated hyperplastic changes without dysplasia and he had no family history of juvenile polyps. We preoperatively diagnosed gastropathy due to huge hyperplasic polyps. Therefore, we performed distal gastrectomy because of two huge polyps causing anemia and hypoproteinemia. Consequently, immediately after surgery, he stopped diarrhea and recovered hemoglobin and serum protein levels although it remained potential malignancy in the remnant stomach. Reviewing retrospectively, it was endoscopically difficult to evaluate coexistence of dysplasia because of a lot of polyps with much mucin but endoscopic findings showed specific for juvenile polyps. Endoscopically, juvenile polyps are soft, edematous, reddish, and lustrous and sometimes with rich mucin and vary in size from a few millimeters to over $5 \mathrm{~cm}$. Histopathology features of juvenile polyps show a normal epithelium with a dense stroma, an inflammatory infiltrate, and a smooth surface with dilated, mucus-filled cystic glands in the lamina propria. It seems difficult to distinguish between juvenile polyp and foveolar hyperplastic polyp histologically by biopsy specimens. Therefore, we think endoscopic findings of JPS, especially juvenile polyposis of the stomach, are important for considering differential diagnosis because of the possibility of bearing malignancy. In addition, polyps in this case were too large and negative for $H$. pylori infection considering foveolar hyperplastic polyps.

\section{References}

1. Latchford AR, Neale K, Phillips RK, Clark SK (2012) Juvenile polyposis syndrome: a study of genotype, phenotype, and long-term outcome. Diseases of the colon and rectum 55(10): 1038-1043.

2. Sachatello CR, Hahn IS, Carrington CB (1974) Juvenile gastrointestinal polyposis in a female infant: report of a case and review of the literature of a recently recognized syndrome. Surgery 75(1): 107-114.

3. Watanabe A, Nagashima H, Motoi M, Ogawa K (1979) Familial juvenile polyposis of the stomach.

4. Hizawa K, Iida M, Yao T, Aoyagi K, Fujishima M (1997) Juvenile polyposis of the stomach: clinicopathological features and its malignant potential. Journal of clinical pathology 50(9): 771-774.

5. Chow E, Macrae F (2005) A review of juvenile polyposis syndrome. J Gastroenterol Hepatol 20(11): 1634-1640.

6. van Hattem WA, Brosens LA, de Leng WW, Morsink FH, Lens S, et al. (2008) Large genomic deletions of SMAD4, BMPR1A and PTEN in juvenile polyposis. Gut 57(5): 623-627.

7. Howe JR, Roth S, Ringold JC, Summers RW, Jarvinen HJ, et al. (1998) Mutations in the SMAD4/DPC4 gene in juvenile polyposis. Science 280(5366): 1086-1088.

8. Zbuk KM, Eng C (2007) Hamartomatous polyposis syndromes. Nat Clin Pract Gastroenterol Hepatol 4(9): 492-502.

9. Nugent KP, Talbot IC, Hodgson SV, Phillips RK (1993) Solitary juvenile polyps: not a marker for subsequent malignancy. Gastroenterology 105(3): 698-700. 
10. Brosens LA, van Hattem A, Hylind LM, Iacobuzio-Donahue C, Romans $\mathrm{KE}$, et al. (2007) Risk of colorectal cancer in juvenile polyposis. Gut 56(7): 965-967.

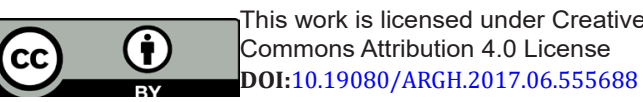

\section{Your next submission with JuniperPublishers will reach you the below assets}

- Quality Editorial service

- Swift Peer Review

- Reprints availability

- E-prints Service

- Manuscript Podcast for convenient understanding

- Global attainment for your research

- Manuscript accessibility in different formats

( Pdf, E-pub, Full Text, audio)

- Unceasing customer service

Track the below URL for one-step submission https://juniperpublishers.com/online-submission.php 